Quantitative tracheid anatomy of Juniperus thurifera reveals a complex environmental control of wood structure under continental

\title{
Mediterranean climate
}

José M. Olano $^{1 *}$, Màrcia Eugenio ${ }^{1}$, Ana I. García-Cervigón ${ }^{1}$, Maika Folch ${ }^{1}$ and Vicente Rozas ${ }^{2}$

${ }^{1}$ Departamento de Ciencias Agroforestales, EU de Ingenierías Agrarias, UVa, Campus Duques de Soria, E-42004 Soria, Spain. ${ }^{2}$ Misión Biológica de Galicia, Consejo Superior de Investigaciones Científicas (MBG-CSIC), Apdo. 28, E-36080 Pontevedra, Spain.

* Corresponding author: jmolano@agro.uva.es. 


\begin{abstract}
A deep understanding of how climate models tree's hydraulic system is nowadays lacking, which is intriguing under the ongoing process of climatic change. To the best of our knowledge, no systematic correlation of tracheid's anatomical features has been implemented in Mediterranean ecosystems where climatic change is expected to be particularly intense. We measured ring widths and the intra-ring position, lumen size, and wall thickness of tracheids in ten Juniperus thurifera individuals from north-central Spain, and we performed an exploratory analysis of their correlations with climatic variables in the period 1965-2004. Cell number and ring widths shared a quite similar climatic signal, whereas anatomical variables provided a differentiated and diverse signal on the climatic conditions during their formation. Earlywood and latewood structure were controlled by different factors. Tracheid anatomical variables improved our understanding of climate effects on tree growth and wood formation under harsh environmental conditions as in Mediterranean continental climates, where limiting factors shift from low temperatures to water deficit several times along the year.
\end{abstract}

Short title: Olano et al. - Complex control of Juniperus tracheid anatomy 


\section{Introduction}

The potential of crossdating to unequivocally relate annual tree rings to calendar years confers tree rings a great value as an accurate proxy of the environmental conditions that affected tree vigor and performance previous to and during their formation (Fonti et al. 2010). Dendrochronology was initially founded on tree-ring width, a variable that constitutes a good measure of plant investment in secondary growth with annual resolution (Schweingruber 1996). Although ring width is widely used in dendrochronological research, the range of parameters characterizing annual rings and susceptible to be measured and used as environmental proxies has notably increased during last decades, including intra- and inter-annual variations of wood density (Rigling et al. 2002; Bureau et al. 2005), content of chemical elements (Novak et al. 2010), stable isotope composition (McCarroll and Loader 2004), and anatomical features (Panyushkina et al. 2003). Consequently, the amount of information retrieved from annual tree rings has progressively increased and conferred dendrochronological techniques a prominent role in the reconstruction of past environmental conditions (Hughes et al., 2011), and in the understanding of plant-environment relationships from a historical perspective (Fritts 1976; Schweingruber 1996).

Xylem anatomical features are the result of a compromise between competing demands for support, storage and transport of water and metabolites under changing environmental conditions and subjected to primary anatomical constraints (Zweifel et al. 2006; Chave et al. 2009). The interest of wood quantitative analysis, i.e., the discipline that deals quantitatively with xylem anatomic features along series of annual rings, has mostly been focused on the hydraulic architecture, given the capital role of xylem as a conductive system, and since the relationship between anatomical and functional characteristics of conductive elements are relatively well known (Sperry 2003). Lumen size determines hydraulic conductivity in such a way that small increases in diameter of conductive elements lead to major gains in hydraulic conductivity, as described by the Hagen-Poiseuille law (Eilmann et al. 2011). However, larger lumen sizes also imply higher vulnerability to cavitation (Tyree and Zimmerman 2002), and consequently, lumen diameter is the result of a trade-off between increasing efficiency and decreasing safety in water conductivity (review by Hacke and Sperry 2001). In addition, vulnerability to cavitation relies on the mechanical strength of conduits, so conductive elements showing a thicker cell-wall provide with higher safety to hydraulic transport system at the expense of higher carbon investments (Hacke and Sperry 2001; Pitterman et al. 2006).

Quantitative xylem anatomy provides large amounts of information per annual ring, including cell position, cell number, cell size, lumen size, cell-wall thickness, and wall-to-lumen ratio (Fonti et al. 2010). Temporal variation of xylogenetic phases determines xylem anatomic 
characteristics, which consequently bear sequential information on environmental conditions controlling cambial activity and cell growth throughout the growing season (Zweifel et al. 2006; Eilmann et al. 2011). Additionally, anatomical features of conductive elements are fixed at different phases of the differentiation process from cambial to xylematic cells, with cell size being fixed during cell-expansion phase, and wall thickness being fixed along the cell-maturing phase (Rossi et al. 2006). How specific environmental signals at different times along the active period did influence cell size and wall thickness is difficult to be established. Our knowledge about xylogenetic processes is currently expanding (Samuels et al. 2006; Rossi et al. 2008; Vaganov et al. 2011), thus improving our ability to estimate the time at which cell features are fixed based on its intra-ring position (García-González and Fonti 2006).

Continental Mediterranean climate is doubly restrictive to plant growth, since growth is limited by cold in winter and drought in summer, which leads to two split optimal growth periods in spring and autumn, when a favorable combination of mild temperatures and water availability occur (Mitrakos 1980; García-Plazaola et al. 1997). Xylogenetic studies on conifers under Mediterranean conditions corroborate these expectations, with a temperature-linked onset of cambial activity in spring, and a reduction or even cessation of xylogenesis along summer, followed by a cambial resumption in autumn (De Luis et al. 2007, Camarero et al. 2010). Such double-stress results in a shifting response of xylem growth to temperature, from positive in spring to negative in summer, and a generalized positive response to summer rainfall (Rozas et al. 2009; Vieira et al. 2009). Nevertheless, our understanding of how Mediterranean trees adjust their xylem anatomy to inter- and intra-annual changes in climatic conditions is still scarce. Existing information suggests that tracheid size is positively related to water availability during the cell formation phase (Vieira et al. 2009; DeSoto et al. 2011), but to the best of our knowledge, no systematic correlation of tracheids' anatomical features to climatic conditions has been established in Mediterranean environments. Such information is relevant, since it contributes to our understanding of physiological adaptations of Mediterranean trees to changing climatic conditions, and also because anatomical features can host climatic signals that are complementary to those encoded by tree-ring widths (Kirdyanov et al. 2003; Panyushkina et al. 2003), thus being potentially useful for climatic reconstructions.

In order to improve our knowledge of how xylem anatomical traits are controlled by climate variations in a Mediterranean environment, and to evaluate its potential usefulness as climatic proxies, we performed an exploratory study in which ring widths, and the intra-ring position, lumen size, and wall thickness of tracheids, were measured in ten Juniperus thurifera individuals, and correlated with climatic variables along the period 1965-2004. Our specific aims were a) assessing whether there is a climatic signal in tracheid anatomical traits, b) checking whether anatomical variables contain similar climatic signals to those of ring width, 
and c) evaluating the potential of anatomical traits to provide with additional environmental information aiding to reconstruct past climate under continental Mediterranean conditions.

\section{Methods}

Study species

Juniperus thurifera L. is a long-lived tree endemic to the western Mediterranean basin, with its most important populations growing under continental Mediterranean climate in Spain and Morocco. Dendroclimatic studies on the species indicate that radial growth is mainly affected by winter rainfall, spring temperature and summer water stress (Bertaudière et al. 1999; Rozas et al., 2009; DeSoto 2010). In our study area, the xylogenetic cycle of $J$. thurifera is known to start in early May and extend until late October, and latewood formation is known to initiate in early August (Camarero et al. 2010).

\section{Study area}

The study area is a 3,300 ha woodland located at Sierra de Cabrejas, $30 \mathrm{~km}$ west of Soria city, in north-central Spain $\left(41^{\circ} 46^{\prime} \mathrm{N}, 02^{\circ} 49^{\prime} \mathrm{W} ; 1,100-1,300 \mathrm{~m}\right.$ altitude). Parent rock is Cretaceous limestone and soils are calcium-rich and shallow. Juniperus thurifera forms open woodlands characterized by a mean density of over 300 trees $\mathrm{ha}^{-1}$, intermingled with pines (Pinus sylvestris and $P$. pinaster) and holm oaks (Quercus ilex). Climate is continental Mediterranean, characteristic of the supra-Mediterranean belt in central Spain (Rivas-Martínez and Loidi 1999). Climatic data on mean monthly temperature and total monthly precipitation for the period 1964-2004 were obtained from Soria meteorological station $\left(41^{\circ} 46^{\prime} \mathrm{N}, 02^{\circ} 28^{\prime} \mathrm{W} ; 1,082 \mathrm{~m}\right.$ altitude). The coldest month is January, showing a mean minimum temperature of $-1.8^{\circ} \mathrm{C}$, and the warmest one is July, showing a mean maximum temperature of $28.1^{\circ} \mathrm{C}$ (Fig. 1). Mean monthly rainfall ranges from $29.2 \mathrm{~mm}$ in August to $58.9 \mathrm{~mm}$ in May.

\section{Dating tree-rings, measuring anatomical features and computing chronologies}

We obtained stem discs at $1.3 \mathrm{~m}$ above-ground out of ten trees that had felt along 2004-2005 winter (see Olano et al. 2008 for details). Stem discs were mechanically surfaced and then manually polished with a series of successively finer grades of sandpaper until xylem cellular structure was clearly visible under binocular lens. On every stem disc, two radii were dated by assigning calendar years to rings based on the identification of characteristic ring sequences (Yamaguchi 1991), and with the help of a previous robust chronology for the same site (Rozas 
et al. 2009). Total ring widths were measured to the nearest $0.001 \mathrm{~mm}$ by using a Velmex sliding-stage micrometer interfaced with a computer. Software COFECHA (Grissino-Mayer 2001) was used to quantitatively check the cross-dating errors.

A $5 \mathrm{~mm}$-wide piece was cut out of every disc along the best cross-dated radius, to obtain permanent histological preparations following Schweingruber and Poschold (2005). Sections thinner than $15 \mu \mathrm{m}$ were cut by means of a sledge microtome $\left(^{\odot}\right.$ H. Gärtner / F.H. Schweingruber), placed on a slide and stained with Alcian Blue (Alcian Blue 1\% solution in 0.7 $\mathrm{N} \mathrm{HCl}$ ) and Safranin (Safranin 1\% water soluble), which results in unlignified cells appearing blue and lignified cells appearing red. Sections were afterwards dehydrated along a series of ethanol at increasing concentrations, washed with xylol and permanently preserved by embedding them into Eukitt ${ }^{\circledR}$ glue. Images on every annual ring were captured with a Nikon D90 digital camera mounted on a Nikon Eclipse 50i optical microscope with x200 magnification. Pixel size was $0.272 \mu \mathrm{m}$. When an annual ring could not be captured in a single photograph, sequential images were merged (PTGUI software version 8.3.10 pro). Image treatment was performed with Image-J v.1.44 software (available at http://rsb.info.nih.gov/ij; developed by Wayne Rasband, National Institutes of Health, Bethesda, MD), including blue channel selection, contrast enhancement and median filter.

Lumen radial diameter (LUM), cell wall thickness (WAL), tracheid radial diameter (CEL), and wall-to-cell radial diameter (WC) were measured for each tracheid along three radii per annual ring (Figure 2A). Cells were assigned to earlywood or latewood according to Mork`s index (Denne, 1988). When latewood like cells occurred in earlywood or vice versa, the earlywoodlatewood boundary was defined after a detailed analysis of the ring; this procedure was only necessary in $0.2 \%$ of the cells. Measurements were normalized to standard numbers of cells (three for earlywood and one for latewood) by using the tracheidogram method (Vaganov 1990), with tgram package (DeSoto et al. 2011) in R environment (R Development Core Team 2011). Earlywood was standardized to only three cells as a compromise between keeping maximal temporal homogeneity in cell formation within each standardized cell-class and obtaining intra-annual information among classes. As a result, we obtained tracheid-size related parameters that corresponded to the average tracheid of each earlywood fraction. Earlywood and latewood growth occurs in split periods (Camarero et al. 2010), and latewood comprises a much lower number of cells than earlywood. Consequently, latewood was standardized to one cell. Cell number for earlywood (CNEW), latewood (CNLW), and total ring (CNR) for each year and tree was obtained after averaging the values calculated for each radius. Ring width of earlywood (RWEW), latewood (RWLW), and total ring width (RWT), were measured on the same radii used for previously mentioned measurements. 
Each raw series of anatomical features and widths was standardized with the ARSTAN software (Cook and Holmes 1996). Earlywood and whole-ring related series were fitted to spline functions characterized by a $50 \%$ frequency response of $20 \mathrm{yr}$, which was flexible enough to reduce the non-climatic variance by preserving high-frequency climatic information (Cook and Peters 1981). Latewood related series showed a very slow declining trend in low-frequency variation, and were standardized simply by dividing each series by its mean value. Residuals were prewhitened by autoregressive modeling, thus obtaining dimensionless indices that represent independent, annual records for each series. The year-by-year arithmetic mean of time series of standardized indices was calculated to obtain a chronology for each measured variable.

\section{Data analysis}

In order to evaluate whether the 22 obtained chronologies (see Table 1 for chronology listing and acronyms) shared the same information, a principal component analysis (PCA) (Legendre and Legendre 1998) was performed with the vegan package (Oksanen et al. 2010) in $R$ environment (R Development Core Team, 2011). PCA aimed to extract a series of orthogonal components expressing the variance contained in our set of growth- and anatomy-related variables (Legendre and Legendre 1998). A scatter plot of the weighting coefficients for the first two PCs displayed clusters of variables with similar information. Pearson's correlations between pairs of chronologies were calculated.

In order to identify those climatic factors related to the indexed chronologies for the period 1965-2004, Pearson's correlations were conducted with monthly temperature and precipitation records from previous November to current August for earlywood related parameters, and from previous November to current October for latewood and whole-ring parameters. A multiple regression was afterwards performed between chronologies corresponding to each measured parameter and monthly temperature and precipitation records; variables were included in the model according to the Wald's forward stepwise procedure. The cut-off value for inclusion in the model was 0.05 , and 0.1 for excluding a previously included variable. Analyses were performed with PASW Statistic v. 18 software (2009. Chicago: SPSS Inc).

Finally, we used structural equation models (SEM) to globally model climatic factors determining earlywood tracheids' size, including the sequential effects of previous tracheids' size. In spite of their strong potential, application of this technique in the context of dendrochronology is still scarce (but see Lupi et al. 2010). These models assess how well data support a set of hypothesized relationships among climatic and anatomical parameters by 
including both direct and indirect relationships (Iriondo et al. 2003; Grace et al. 2010). According to multiple regressions, five climatic predictors were included in the model: February and April temperatures, and March, June and July rainfall. Endogenous variables met multinormality, and estimation was based on maximum likelihood estimates. Validity of the model was tested by Goodness-of-Fit Index (GFI) and Root Mean Square Error of Approximation (RMSEA). GFI is independent of estimation methods, and ranges between 0 and 1, with values above 0.90 indicating good fit (Tanaka 1987). RMSEA is based on predicted versus observed covariances, being less affected by sample size, and including a correction for model complexity. RMSEA is less than 0.05 for very good models (close fit), less than 0.1 for models that fit adequately, and larger than 0.1 for poorly-fitted models. Analyses were conducted by the procedure AMOS 5.0 (Arbuckle 2003).

A multiple regression following previously described methodology was performed to assess whether climatic signals recorded in different anatomical parameters may be used together to improve our ability to reconstruct climate. More specifically, June rainfall was modeled against the indexed chronologies of WAL1, WAL2 and CEL2.

\section{Results}

Tree ring widths crossdated satisfactorily, with average correlation of RWT chronology with the previously available master chronology of $0.503(p<0.001)$. Tree age ranged from 71 to $111 \mathrm{yr}$ (mean $\pm \mathrm{SD}, 86 \pm 4 \mathrm{yr}$ ); cambial age at $1.3 \mathrm{~m}$ ranged from 40 to $68 \mathrm{yr}(55 \pm 3 \mathrm{yr}$ ). Chronologies for tree-ring widths and cell numbers in the total ring and the earlywood showed moderately high values of SNR, $r_{b t}$ and climatic $R^{2}$ (Table 1), but chronologies for latewood showed very low statistics and a weak climatic signal. The mean sensitivity of the series, however, is similar among tree ring compartments, being higher for earlywood and lowed for latewood. Chronology statistics for tracheid and lumen diameters, wall thickness, and wall-to-cell ratios were considerably lower than for ring widths and cell numbers. Noticeably, the statistical quality of anatomical variables was higher in the 2nd and 3rd parts of the earlywood, than in the 1 st part of the earlywood and the latewood.

A total of 44,131 cells from 1,191 cell rows were measured. An average of 101.16 cells for earlywood and 11.26 cells for latewood were measured per ring and tree. Latewood comprised $9.2 \%$ of the total number of tracheids within a ring, but only $3.9 \%$ of total tree-ring width. Average tracheid size decreased along the ring from $18.19 \mu \mathrm{m}$ for the first third of earlywood to $6.31 \mu \mathrm{m}$ for latewood (Table 1, Figure 2B). Radial diameter of lumen followed a similar pattern, also showing an abrupt reduction in the transition from earlywood to latewood. Wall thickness showed small changes along earlywood and a small decrease (16.6\%) from earlywood to 
latewood. Contribution of wall-to-tracheid size almost doubled from the third part of earlywood to latewood.

\section{Chronologies ordination}

The first PCA axis explained $58.10 \%$ of the variance of anatomical and width variables, and showed a clear distinction between earlywood and total tree ring, for both width and cell number, from the other anatomical parameters (Fig. 3A). The second PCA axis explained 29.16 $\%$ of the variance, and differentiated latewood cell number and width from the rest of variables. Interestingly, cell number and width chronologies shared almost the same information, as shown by the high correlations between both chronologies for earlywood $\left(r^{2}=0.92\right)$, latewood $\left(r^{2}=0.84\right)$ and total ring $\left(r^{2}=0.95\right)$, all of them significant at 0.001 level. The close position of earlywood and total ring width in cell-number chronology is probably a consequence that earlywood represents $96.1 \%$ of total ring width, i.e. $90.8 \%$ of total number of cells. Anatomical parameters related to tracheid size, wall thickness, and wall-to-cell ratio showed a clumped distribution in the lowest values of both PCA axes, suggesting that their chronologies may share similar climatic signals, but different from cell number and width chronologies (Fig. 3A). In order to assess the relationships between those anatomical parameters within a tree ring, a separate PCA was performed, with the first two PCA axes comprising $61.88 \%$ of the variance (Fig. 3B). Wall-to-cell ratio showed a separate position at the top of the diagram, while earlywood lumen and cell-size parameters appeared at the bottom of the diagram, close to each other. This pattern is consistent with the high correlations between earlywood tracheid lumen and size $\left(r^{2}=0.95, p<0.001\right)$, suggesting that both parameters shared a common environmental signal. Wall thickness, however, showed an intermediate position between tracheid size and wall-to-cell ratio. Latewood tracheid size, lumen size and wall thickness were isolated at the right of the diagram, suggesting also a particular environmental signal differentiated from the other anatomical variables.

\section{Climatic control of wood anatomy and radial growth}

Cell number in both the complete ring and the earlywood were positively correlated to April temperature and July rainfall, and negatively correlated to winter rainfall, since previous December to current March (Fig. 4). Regression models reduced the number of significant variables to precipitation in July (positive), December (negative), and February (negative), overall explaining near 38\% of cell number variance (Table 1). Climate-growth relationships for earlywood and total tree-ring widths were quite similar to their corresponding cell numbers. Earlywood and total ring widths showed negative correlations with winter rainfall, and positive 
correlations with summer rainfall and April temperature. Regression models for earlywood and total ring widths reduced the number of significant variables to April temperature (positive, earlywood), and precipitation in June (positive, total), previous December (negative, total), February (negative, both), and March (negative, earlywood). Overall, these variables explained higher variance for ring widths than for cell number; $42.4 \%$ for earlywood width, and $45 \%$ for total ring width. Latewood cell number was inversely correlated to previous December temperature, and latewood ring width was directly correlated to June temperature. Regression models for latewood-related parameters were poorer than for earlywood and total ring ones, and included a negative effect of previous December temperature on cell number, and a positive effect of June temperature on width. These models explained $18.6 \%$ of total variance in the case of latewood cell number, and $29.9 \%$ in the case of latewood width (Table 1).

Earlywood tracheid diameters were positively correlated to February temperature and negatively correlated to March rainfall (Fig. 5). CEL2 was positively correlated to June rainfall and April temperature and negatively correlated to June temperature. July temperature showed a negative effect on CEL3, whereas June and July precipitation showed a positive effect, and August temperature exerted a positive effect on CELLW. Percentage of total variance explained by multiple regression models was low for CEL1 (12.4\%), but high for CEL2 (41\%) and (24.9\%) and again low for CELLW (14\%) (Table 1). Climate-growth models for earlywood lumen diameter were almost identical to tracheid diameter models, but the explained variance was lower, except for LUMLW that showed an additional negative effect of November temperature, with a total explained variance of $26.6 \%$ (Fig 5, Table 1).

Earlywood wall thickness was positively correlated to rainfall during its formation, shifting from June for WAL1 and WAL2 to July for WAL3. The final part of the earlywood had also a negative signal of previous November-December temperature and precipitation. Latewood wall thickness (WALLW) was positively related to October rainfall, and all anatomical variables of LW showed significant positive relationships with August temperature. Regression models reveled significant effects of the same variables previously mentioned (Table 1, Fig 5).

Wall-to-cell ratios showed no significant correlations for WC1, whereas WC2 was positively correlated to March rainfall $(\mathrm{r}=0.35, p<0.025)$, WC3 was correlated to both previous November $(\mathrm{r}=0.35, p<0.025)$ and current October rainfall $(\mathrm{r}=0.35, p<0.025)$. Finally, WCLW was positively correlated to July rainfall $(\mathrm{r}=0.39, p=0.016)$. The parameters included in regression models only differed for WCLW, since an additional negative effect of February temperature was observed, with a total explained variance of $27.6 \%$.

SEM model provided a good overall fit for our data set (Fig. 6). Probabilities of chi-square estimates were greater than $0.05\left(\mathrm{df}=16, \chi^{2}=17.930, p=0.328\right)$, GFI was over $0.90(0.909)$ 
and RMSEA lower than $0.1(0.056)$. Power of the model was mainly due to the robust sequential relationship between earlywood tracheid diameters. Second (CEL2) and third (CEL3) tracheid diameters were strongly dependent on first (CEL1) tracheid diameter. Tracheid diameter was affected by different climatic factors throughout the ring. CEL1 increased after warm February, whereas CEL2 and CEL3 were positively affected by June and July rainfall, respectively. March rainfall effect on CEL2 and CEL3 was non-significant, whereas April temperature showed a significant positive effect on CEL2.

Multiple regression model for June rainfall was highly significant ( $\mathrm{df}=37, F=11.879, p<$ $0.001)$, and included CEL2 $(\mathrm{t}=3.124, p=0.003)$ and WAL1 $(\mathrm{t}=3.002, p=0.005)$, but not WAL2, since its information was redundant with that of CEL2 (partial correlation with June P; $r$ $=0.23, p=0.15)$. The simultaneous use of two proxies resulted in an important gain in explained variance after using this regression model, since $r_{\text {adj }}^{2}$ increased from $22.3 \%$ to $35.8 \%$, with a relative increase of $60.5 \%$ from the best single estimator.

\section{Discussion}

Tracheid anatomical features provide information that reflects environmental conditions during xylogenesis, and particularly during the cell-expansion and cell-maturation phases, expressing with high temporal resolution the shift in the climatic signal throughout the complete period of formation of a tree ring. Information retrieved from anatomical features was unrelated to that present in ring width chronology. Contrastingly, cell number-based chronologies were strongly related to ring-width ones. Thus, the combined use of cell numbers and tracheid anatomical features in Juniperus thurifera significantly improved our capacity to assess and model the effects of limiting climatic conditions in continental Mediterranean environments.

\section{Climatic control of anatomical features}

The range of variation of the measured anatomical features is strongly constrained by their functionality and, thus, the observed low sensitivity of anatomical variables, in comparison to ring widths, could be previously expected. However, small variations in wood anatomy may show both a strong impact in xylem properties, and a significant dependence on climate variability. Nevertheless, quality control statistics of the anatomical chronologies were also reduced in comparison with ring width-based chronologies, particularly for wall thickness and wall-to-cell ratio. This result might suggest that tracheid-based chronologies should be based in larger sample depths to attain similar reliability to ring width-based chronologies, which imply a huge effort in comparison to the measurement of ring widths usually performed in 
dendroclimatic studies. The suitability of the measured anatomical parameters needs to be carefully evaluated, since previous studies have shown that, even with very low inter-tree correlations and common signals, strong and sound climatic responses can be found in anatomical variables (Yasue et al. 2000). A reason for the weak common signal in these variables may be due to the low inter- and intra-individual variability of these, in comparison to ring widths.

Our results highlight that tracheid size at the beginning of xylogenesis depends on the conditions during late winter, with larger tracheids occurring after a warmer February. A strong signal of climatic conditions previous to the onset of the growing period and negatively influencing the size of conductive elements has already been described in ring-porous trees, and has been interpreted as an increasing sensitivity of overwintering cambial derivates by fostering the reactivation of auxin carriers (Fonti et al. 2007). Since tracheid size is highly correlated within the earlywood along a radial file, the climatic signal influencing tracheid size at the beginning of the xylogenesis is maintained along the whole earlywood, probably leading to spurious correlations of cell size with February temperature and March rainfall along the complete earlywood. Tracheid size is also controlled by conditions during the cell-expansion phase, which occurs during a brief period immediately following cell differentiation (Gričar 2009). Tracheids expand sequentially, which leads to a temporal shift in the climatic conditions recorded by cell size during the expansion phase. The temporal shift is displayed by the climatic responses for CEL1, CEL2 and CEL3, with rainfall effects on cell size moving from June in the second segment of the earlywood to July in the third segment. This timing is in accordance with previous knowledge on the phenology of earlywood tracheid enlargement for J. thurifera, which occurs from May to July (Camarero et al. 2010). The absence of significant effect of rainfall on cell formation in the first segment of the earlywood might be related to the relatively low water stress that characterizes May when such cells are formed. Water deficit conditions in May occur just in 5\% of the years, compared to $50 \%$ in June and $70 \%$ in July.

Two complementary mechanisms may explain, at least partially, the critical role of water availability for cell size. Firstly, since cell turgor is associated with water supply during the cellexpansion phase, cell enlargement could be mainly due to a direct effect of short-term water availability (Kramer 1964; Von Wilpert 1991). Secondly, since plants respond to water stress by enhancing abscisic acid (ABA) production, an indirect effect of water availability on cell size mediated by fitohormones is also likely (e.g., Xiong et al. 2002). ABA is involved in controlling the size of xylem conductive cells by blocking the action of indole-3-acetic acid (IAA), which in turn is responsible for tracheid expansion (Little and Savidge 1987). Although the details of the mechanisms involved in the process of cell expansion are still under discussion (Vaganov et al. 2011), it would lead to an optimum adjustment of the hydraulic system to water availability. 
Similarly, wall thickness was also controlled by June-July rainfall, but there was a minor delay in the timing, since in the early earlywood was correlated to June rainfall, whereas in the late earlywood it was affected by July rainfall. Such time-lag could be related to the fact that cellmaturing phase in our study area, including wall thickening, initiates immediately after full cell expansion, which typically occurs during June and July (Camarero et al. 2010). Although final lumen size is fixed at the same time than wall thickness, earlywood lumen diameter chronologies and climatic response were almost identical to those corresponding to tracheid diameter (Fig. 5). This may be related to the fact that lumen diameter of earlywood cells is closely linked to tracheid diameter $(r=0.98, p<0.001, n=44,131)$, but shows little correlation to wall thickness $(r=0.19, p<0.001, n=44,131)$, which suggests that cell size, but not the thickness of its wall, is determined during cell expansion phase.

Juniperus thurifera, as other evergreen Mediterranean conifers, is able to maintain the photosynthetic activity during the whole year (Larcher 2000). Trees accumulate carbohydrates in winter that are stored and subsequently allocated to earlywood formation in spring, after cambial reactivation (Kagawa et al. 2006). Seasonal variation of carbohydrates in Juniperus thurifera stems is coherent with this hypothesis, with resources being accumulated during winter and subsequently depleted at the start of xylogenesis (Camarero et al. 2010, DeSoto 2010). The observed climate-growth relationships suggest that cambial activity is strongly affected by winter conditions, particularly rainfall since December to March. The number of cells is higher after dry winters, a fact that has been previously interpreted as the effect of cloudy and snowy conditions during wet winters, and subsequent reduction of both maximum daily temperatures and solar radiation received by the trees, which results in reduced photosynthetic rates and cambial activity (DeSoto 2010; Rozas et al. 2009). A prolonged growing season caused by an earlier onset of xylogenesis resulting from warm April conditions, and improved division rates resulting from rainy summer conditions (Camarero et al. 2010), may also determine total cell number and ring widths.

A certain degree of dissimilarity in the climatic signal shown by earlywood and latewood chronologies was expected, given the distinct phenology of their xylogenesis (see Camarero et al. 2010). Nevertheless, the strong differential signal observed is related to a dramatic change in the factors controlling tracheid development, showing a shift from a positive control of water availability during June-July in earlywood, to a positive control by August-September temperature in latewood. This relationship might seem similar to that observed in alpine environments, where latewood formation is limited by summer temperature, with cool summers leading to "light rings", almost completely constituted by earlywood (Gindl 1999; Yasue et al. 2000; Wang et al. 2002). Nevertheless, our results on $J$. thurifera are not comparable, since 
temperature exerts a positive effect both on wall thickness and lumen size which does not necessarily lead to "dense" rings.

Results on latewood parameters should be interpreted with caution due to the low inter-annual and inter-individual variability that suggest the need of a much larger sample depth than used in this exploratory study. A potential interpretation is that our results reflect the different nature of latewood in junipers compared to other gymnosperms. J. thurifera showed a very low percentage of latewood in annual rings and wall thickness barely varied along the complete tree ring. Both evidences suggest that latewood may simply result from a reduction of tracheid enlargement at the end of growing season, more than a true differentiation of a particular cell type characteristic of the latewood, as it is usual in other conifers, i.e. with considerably higher wall thickness of latewood than earlywood cells (Yasue et al. 2000). Usually, earlywood has ca. 11 times the specific conductivity of latewood and up to $90 \%$ of the total water flow occurs through the earlywood, but latewood has a lower vulnerability to embolism playing a strong role on hydraulic security (Domec and Gartner 2002). In addition, latewood shows higher density and a key structural function, its formation constituting a sink for carbohydrates, since it requires a continuous supply of energy either from storage tissues or produced by photosynthesis (Oribe et al. 2003). However, the small size of J. thurifera trees, with a maximum height of about $11 \mathrm{~m}$ in the study site (Rozas et al. 2009), the high specific conductivity and low vulnerability to embolism of its earlywood (Willson et al. 2008), and the exiguous carbohydrate availability in a very restrictive environment, may reduce the need for these latewood functions, explaining the reduced development of latewood in this species.

\section{Potential of anatomical features as climate proxies}

In accordance with our findings, a close link between tree ring width and cell number has been previously described for gymnosperm tree species (Gregory 1971; Camarero et al., 1998). Ring width can be interpreted as resulting from the combination of cell number, determined by the rates of cambial activity, and cell size, determined during the process of cell expansion, and therefore it should encode similar information to that encoded by both parameters. Relative strength of tracheid number and size in determining tree ring width may be species- or even context-dependent (Wang et al. 2002; Panyushkina et al. 2003). In our case, the low variability found in tracheid diameters as compared to cell number caused the observed close relationship between cell number and ring width chronologies, and between their respective climatic signals. Therefore, a separate analysis of climatic signals related to cell number and tracheid diameter provided a more powerful tool to understand tree climatic sensitivity of wood structure than 
solely tree-ring width chronologies. Moreover, this analysis allowed to obtain a higher number of climatic proxies, but also several proxies for the same climatic parameter, that may be used together (Meko et al. 1980). The diversification of biological proxies of different nature allowed to improve the power of models calculated to perform climatic reconstructions, as has been shown in the present work for June rainfall, with an additional $13.5 \%$ of explained variance when the anatomical variables were accounted for.

Lumen diameters and wall-to-cell ratios generally show a direct functional meaning related to xylem hydraulic properties, such as conductivity or resistance to implosion (Tyree and Zimmerman 2002). Consequently, they constitute standard measurements in ecophysiological studies (Hacke and Sperry, 2001), which have been recently incorporated in dendroclimatic studies on conifers (Fonti et al. 2010). Nevertheless, since these parameters result from the combined effects of two separate xylogenetic processes, namely tracheid expansion and maturation, interpretation of their link to particular climatic parameters is complex. In this sense, the use of tracheid diameter and wall thickness seems more straightforward, since they respond to prevailing climatic conditions during cell expansion and maturation phases, respectively. Consequently, we suggest that the use of these or other simple anatomical parameters could be appropriate to evaluate the intra-seasonal climatic influence on anatomical features during xylogenesis. In this respect, the use of climatic variables with a more short temporal resolution than standard records of monthly time series given by the meteorological stations would probably be promising. The inclusion of derived variables, such as lumen diameter or wall-to-cell ratios, should be accomplished in the context of adequate statistical techniques, such as structural equation modelling, where the additive effect of different climatic parameters on these features throughout cell expansion and wall thickening can be satisfactorily incorporated.

Standardization through the tracheidogram method allowed tree rings with different cell numbers to be comparable (Vaganov 1990). However, cambial activity initiation, intensity and duration can show strong yearly, intra-annual, and even inter-individual variability (Lupi et al. 2010). Thus, standardization to a common number of cells does not ensure that cells in the same position have been formed simultaneously. In spite of a previous, accurate knowledge of xylogenesis in our study species, this uncertainty increases as the number of standardized cells does. The number of standardized cells is a compromise between the required intra-annual temporal resolution and the temporal homogeneity in the within-ring cell position. Consequently, the number of standardized tracheids to generate from raw data is a key aspect in climatic studies of anatomical features. The optimum number will depend on the specific goals of the study, and should be kept low enough to guarantee a high within-standardized tracheid 
temporal homogeneity if the goal is assessing climate-growth relationships or obtaining a reliable proxy for climatic reconstruction.

\section{Conclusions}

The combination of anatomical features, cell number and ring width data depicted the existence of a multiplicity of factors controlling secondary growth under a Mediterranean continental climate. Winter conditions, mainly due to negative effects of rainfall-related conditions on cambial activity rates, determine the pattern of carbohydrate accumulation before cambial activity onset, affecting final ring widths Late winter temperature serves as a cue for initial tracheid size and warm spring temperature determines the onset of cambial activity. Cambial activity and intensity, as well as earlywood tracheid and wall size are positively related to early summer rainfall, whereas latewood tracheid and wall features are positively controlled by late summer temperature. Our exploratory study shows the strong potential of anatomical-based chronologies to improve our understanding of climatic effects on growth and tree ring formation under really complex situations as in Mediterranean continental climates where multiple control factors shift along the year. Moreover, our ability to reconstruct past climatic time series may be greatly enhanced by using novel climatic proxies and particularly by the existence of multiple uncorrelated biological proxies of the same climatic parameters. Further research should focus on confirming and validate a general applicability of tracheid-based chronologies in Mediterranean environments. Finally, our study reinforces the potential use of SEM models in the context of dendrochronology.

\section{Acknowledgements}

We are especially indebted to Gonzalo Juste for the arduous task of tracheid measurements. V.R. was supported by a research contract from CSIC. This work has been supported by the Spanish Ministerio de Ciencia e Innovación project ISLAS CGL2009-13190-C03-03 and Junta de Castilla y León project VA006A10-2.

\section{Literature cited}

Arbuckle JL 2003 Amos 5.0 Update to the Amos User's Guide. Smallwaters Corporation, Chicago.

Bertaudière V, N Montès, T Gauquelin, J-L Édouard 1999 Dendroécologie du genévrier thurifère (Juniperus thurifera L.) exemple de la thuriféraie de la montagne de Rié (Pyrénées, France). Ann For Sci 56:685-697. 
Bouriaud O, J-M Leban, D Bert, C Deleuze 2005 Intra-annual variations in climate influence growth and wood density of Norway spruce. Tree Physiol 25:651-660.

Camarero JJ, J Guerrero-Campo, E Gutierrez 1998 Tree-ring growth and structure of Pinus uncinata and Pinus sylvestris in the Central Spanish Pyrenees. Arctic Alpine Res 30:1-10.

Camarero J, JM Olano, A Parras 2009. Plastic bimodal xylogenesis in conifers from continental Mediterranean climates. New Phyt 185:471-480.

Chave J, D Coomes, S Jansen, SL Lewis, NG Swenson, AE Zanne 2009 Towards a worldwide wood economics spectrum. Ecol Lett 12:351-366.

Cook ER, RL Holmes 1996 Guide for computer program ARSTAN. Pages 75-87 in HD Grissino-Mayer, RL Holmes, HC Fritts, eds. The international tree- ring data bank program library version 2.0 user's manual. Laboratory of Tree-Ring Research, University of Arizona, Tucson. USA.

Cook ER, K Peters 1981 The smoothing spline: a new approach to standardizing forest interior tree-ring width series for dendroclimatic studies. Tree-Ring Bull 41:45-53.

DeLuis M, J Gričar, K Čufar, J Raventós 2007 Seasonal dynamics of wood formation in Pinus halepensis from dry and semi-arid ecosystems in Spain. IAWA J 28:389-404.

Denne MP 1988 Definition of latewood according to Mork (1928). IAWA Bull 10:59-62.

DeSoto L 2010 Global change effect on the dioecious tree Juniperus thurifera in the Iberian Peninsula. PhD diss. University of Valladolid, Soria, Spain.

DeSoto L, M De la Cruz, P Fonti 2011 Intra-annual pattern of tracheid size in the Mediterranean Juniperus thurifera as indicator for seasonal water stress. Can J For Res 41:1280-1294.

Domec JC, BL Gartner 2002 How do water transport and water storage differ in coniferous earlywood and latewood? J Exp Bot 53:2369-2379.

Eilmann B, R Zweifel, N Buchmann, E Graf Pannatier, A Rigling 2011 Drought alters timing, quantity, and quality of wood formation in Scots pine. J Exp Bot 62, 2763-2771.

Fonti P, I García-González 2004. Suitability of chestnut earlywood vessel chronologies for ecological studies. New Phyt 163:77-86.

Fonti P, N Solomonoff, I García-González 2007 Earlywood vessels of Castanea sativa record temperature before their formation. New Phyt 173:562-70.

Fonti P, G von Arx, I García-González, B Eilmann, U Sass-Klaassen, H Gärtner, D Eckstein 2010 Studying global change through investigation of the plastic responses of xylem anatomy in tree rings. New Phyt 185:42-53.

Fritts HC 1976 Tree rings and climate. Kluwer Academic, New York

Garcia-Plazaola JI, T Faria, J Abadia, A Abadia, MM Chaves, JS Pereira 1997 Seasonal changes in xantophyll composition and photosynthesis of cork oak (Quercus suber L.) leaves under Mediterranean climate. J Exp Bot 48:1667-1674.

García-González I, Fonti P 2006 Selecting earlywood vessels to maximize their environmental signal. Tree Physiol 26:1289-1296.

Gindl W 1999 Climatic significance of light rings in timberline spruce, Picea abies. Arctic Alpine Res 31:242-246.

Grace JB, TM Anderson, H Olff, SM Scheiner 2010 On the specification of structural equation models for ecological systems. Ecol Monogr 80:67-87.

Gregory RA 1971 Cambial activity in Alaskan white spruce. Am J Bot 58:160-171.

Gričar J 2009 Significance of intra-annual studies of radial growth in trees. In R Kaczka, I Malik, P Owczarek, H Gärtner, G Helle, J Heinrich, eds. TRACE - Tree Rings in Archaeology, Climatology and Ecology. Vol 7. Proceedings of the Dendrosymposium 2008, April 27th - 30th 2008. GFZ, Zakopane, Poland.

Grissino-Mayer HD 2001 Evaluating crossdating accuracy: A manual and tutorial for the computer program COFECHA. Tree-Ring Res 57:205-221.

Hacke UG, JS Sperry 2001 Functional and ecological xylem anatomy. Perspect Plant Ecol $4: 97-115$. 
Hughes MK, TW Swetnam, HF Diaz 2011 Dendroclimatology: Progress and Prospects. Springer Verlag, New York.

Iriondo JM, MJ Albert, A Escudero 2003 Structural equation modelling: an alternative for assessing causal relationships in threatened plant populations. Biol Conserv 113:367-377.

Kagawa A, A Sugimoto, TC Maximov $2006{ }^{13} \mathrm{CO}_{2}$ pulse-labelling of photoassimilates reveals carbon allocation within and between tree rings. Plant Cell Environ 29:1571-1584.

Kirdyanov A, M Hughes EA Vaganov, F Schweingruber, P Silkin 2003 The importance of early summer temperature and date of snow melt for tree growth in the Siberian Subartic. Trees 17:61-69.

Kramer, PJ 1964 The role of water in wood formation. Pages 519-532 in MH Zimmermann, ed. The formation of wood in forest trees. Academic Press, New York. USA.

Larcher W 2000 Temperature stress and survival ability of Mediterranean sclerophyllous plants. Plant Biosyst 134:279-295.

Legendre P, L Legendre 1998 Numerical Ecology. Elsevier, Amsterdam.

Little CHA, RA Savidge 1987 The role of plant growth regulators in forest tree cambial growth. Plant Growth Regul 6:137-169.

Lupi C, H Morin, A Deslauriers, S Rossi 2010 Xylem phenology and wood production: resolving the chicken-or-egg dilemma. Plant Cell Environ 33:1721-1730.

McCarroll D, NJ Loader 2004 Stable isotopes in tree rings. Quat Sci Rev 23:771-801.

Meko DM, CW Stockton, WR Boggess 1980 A tree-ring reconstruction of drought in southern California: Water Resources Bulletin 16:594-600.

Mitrakos KA 1980 A theory for Mediterranean plant life. Acta Oecol 1:245-252.

Novak M, J Mikova, M Krachler, J Kosler, L Erbanova, E Prechova, I Jackova, D Fottova 2010 Radial distribution of lead and lead isotopes in stem wood of Norway spruce: A reliable archive of pollution trends in Central Europe. Geochim Cosmochim Ac 74:4207-4218.

Oksanen J, FG Blanchet, R Kindt, P Legendre, RB O'Hara, GL Simpson, P Solymos, MH Stevens, H Wagner 2010 vegan: Community Ecology Package. R package version 1.17-4. http://CRAN.R-project.org/package=vegan.

Olano JM, V Rozas, D Bartolomé, D Sanz 2008 Effects of changes in traditional management on height and radial growth patterns in a Juniperus thurifera $\mathrm{L}$. woodland. For Ecol Manage 255:506-512.

Oribe Y, R Funada, T Kubo 2003 Relationships between cambial activity, cell differentiation and the localisation of starch in storage tissues around the cambium in locally heated stems of Abies sachalinensis (Schmidt) Masters. Trees 17:185-192.

Panyushkina IP, MK Hughes, EA Vaganov, MAR Munro 2003 Summer temperature in northeastern Siberia since 1642 reconstructed from tracheid dimensions and cell numbers of Larix cajanderi. Can J For Res 33:1905-1914.

Pittermann J, JS Sperry, J Wheeler, U Hacke, E Sikkema 2006 Mechanical reinforcement of tracheids compromises the hydraulic efficiency of conifer xylem. Plant Cell Environ 29:1618-1628.

R Development Core Team 2011 R: A Language and Environment for Statistical Computing. R Foundation for Statistical Computing, Vienna.

Rigling A, OU Braker, G Schneiter, FH Schweingruber 2002 Intra-annual tree-ring parameters indicating differences in drought stress of Pinus sylvestris forests within the Erico-Pinion in the Valais (Switzerland). Plant Ecol 163:105-121.

Rivas-Martínez S, J Loidi 1999 Bioclimatology of the Iberian Peninsula. Itin Geobot 13:41-47.

Rossi S, A Deslauriers, T Anfodillo 2006 Assessment of cambial activity and xylogenesis by microsampling tree species: an example at the Alpine timberline. IAWA J 27:383-394.

Rossi S, A Deslauriers, J Griçar, J-W Seo, CB Rathgeber, T Anfodillo, H Morin, T Levanic, P Oven, R Jalkane 2008 Critical temperatures for xylogenesis in conifers of cold climates. Global Ecol Biogeogr 17:696-707.

Rozas V, L DeSoto, JM Olano 2009 Sex-specific, age-dependent sensitivity of tree-ring growth to climate in the dioecious tree Juniperus thurifera. New Phyt 182:687-697.

Samuels AL., M Kaneda, H Rensing 2006 The cell biology of wood formation: from cambial divisions to mature secondary xylem. Can J Bot 84:631-639. 
Schweingruber FH 1996 Tree Rings and Environment. Dendroecology. Paul Haupt Publ, Berne. Sperry JS 2003 Evolution of water transport and xylem structure. Int J Plant Sci 164:115-127.

Tanaka JS 1987. "How big is enough?": Sample size and goodness of fit in structural equation models with latent variables. Child Development 58:134-146.

Tyree MT, MH Zimmerman MH 2002 Xylem structure and the ascent of sap. $2^{\text {nd }}$ edn. SpringerVerlag, New York, USA.

Vaganov EA 1990 The tracheidogramm method in tree-ring analysis and its application. Pages 63-76 in ER Cook, LA Kairiukstis, eds. Methods of dendrochronology. Applications in the environmental sciences. Kluwer Academic Publishers, Dordrecht.

Vaganov EA, KJ Anchukaitis, MN Evans 2011 How well understood are the processes that create dendroclimatic records? A mechanistic model of the climatic control on conifer treering growth dynamics. Pages 37-75 in MK Hughes, TW Swetnamm, HF Diaz, eds. Dendroclimatology: Progress and Prospects. Vol 2(1). Springer Verlag, New York, USA.

Vieira J, F Campelo, C Nabais 2009 Age-dependent responses of tree-ring growth and intraannual density fluctuations of Pinus pinaster to Mediterranean climate. Trees 23:257-265.

Von Wilpert K 1991 Intra annual variation of radial tracheid diameters as a monitor of site specific water stress. Dendrochronologia 9:95-114.

Wang L, S Payette, Y Bégin 2002 Relationships between anatomical and densitometric characteristics of black spruce and summer temperature at tree line in northern Quebec. Can J For Res 32:477-486.

Willson CJ, PS Manos, RB Jackson 2008 Hydraulic traits are influenced by phylogenetic history in the drought-resistant, invasive genus Juniperus (Cupressaceae). Am J Bot 95:299314.

Xiong L, KS Schumaker, J-K Zhu 2002 Cell signaling during cold, drought, and salt stress. Plant Cell 14:S165-S183.

Yamaguchi DK 1991 A simple method for crossdating increment cores from living trees. Can J For Res 21:414-416.

Yasue K, R Funada, O Kobayashi, J Ohtani 2000. The effects of tracheid dimensions on variations in maximum density of Picea glehnii and relationships to climatic factors. Trees 14:223-229.

Zweifel R, L Zimmermann, F Zeugin, DM Newbery 2006 Intra-annual radial growth and water relations of trees: implications towards a growth mechanism. J Exp Bot 57:1445-1459. 


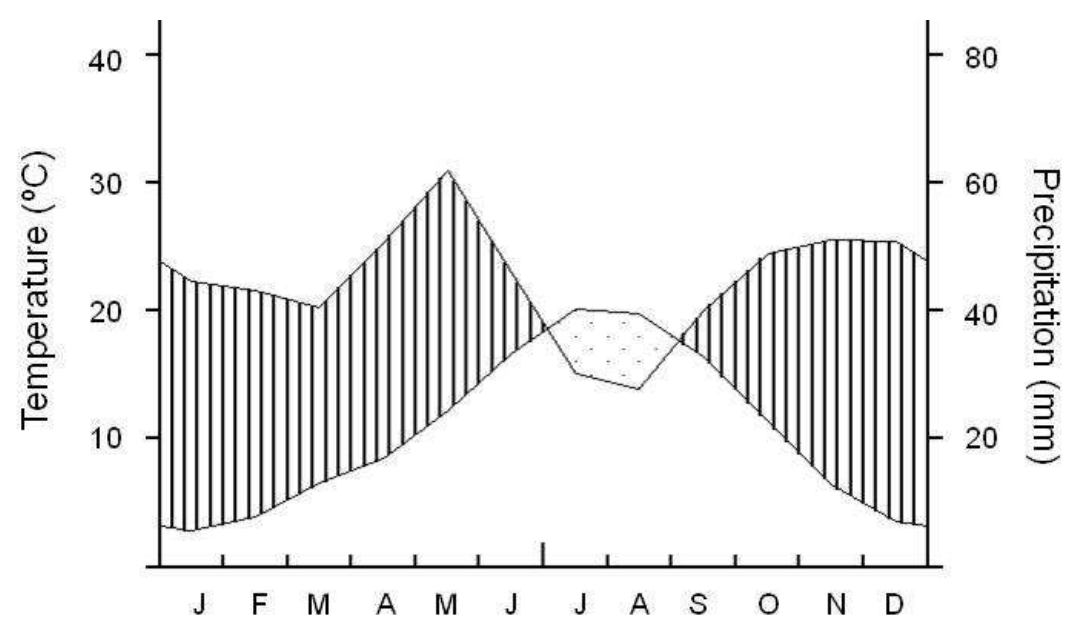

Figure 1. Climatic diagram from Soria meteorological station for the period 1944-2010. 


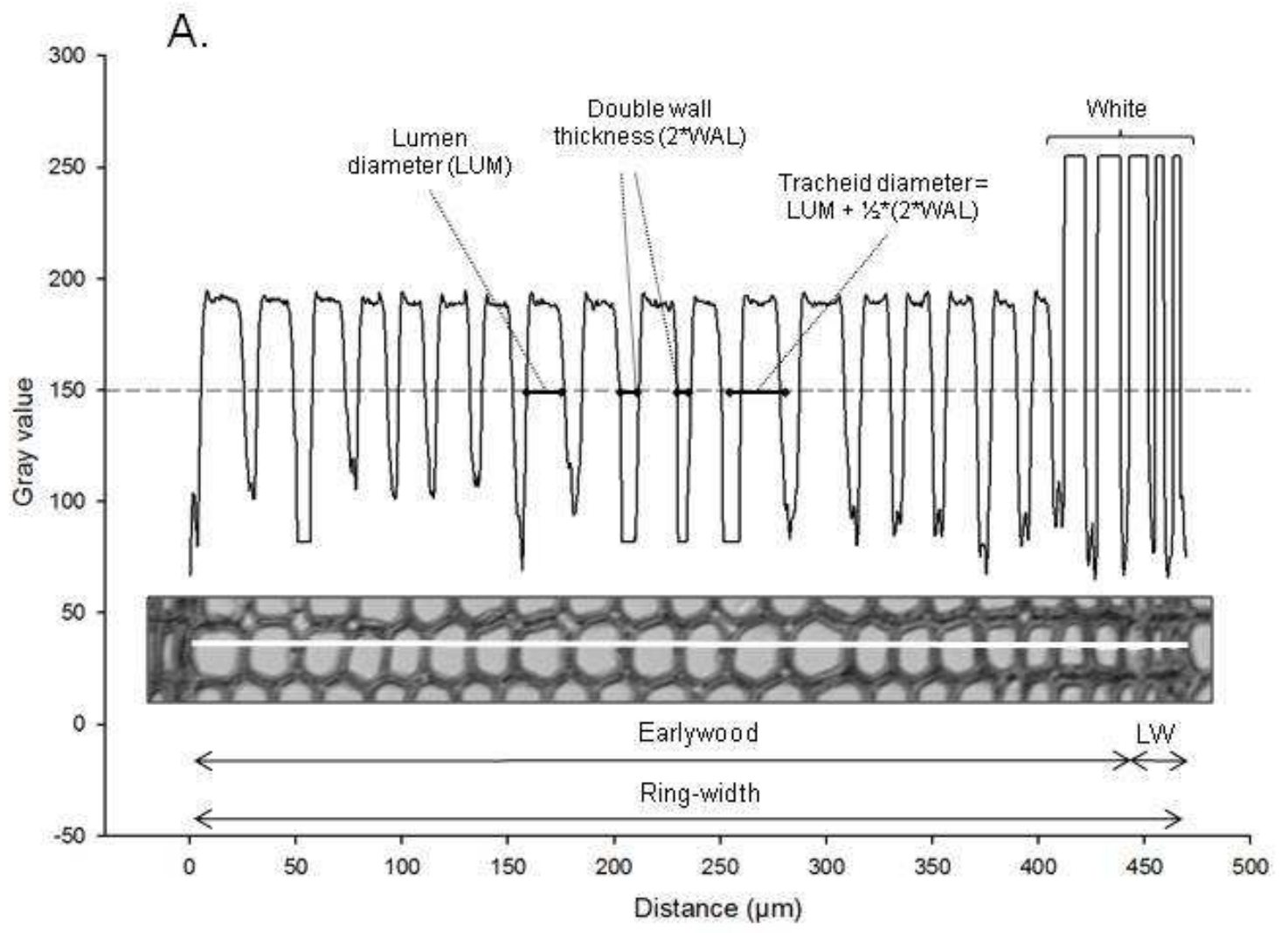

B.

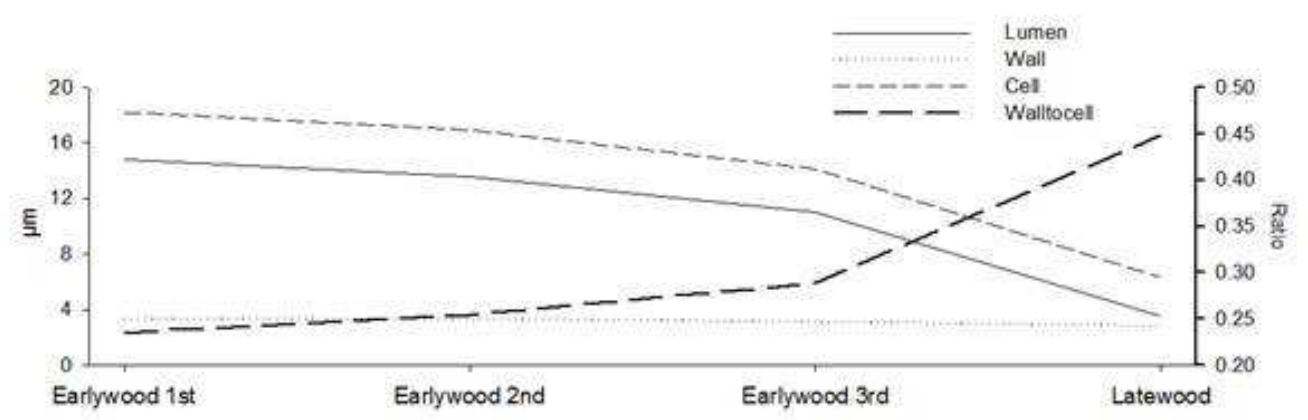

Figure 2: A. Anatomical parameters measurement procedure. The image represents a complete tree ring. Pixel gray values ( 0 black - 256 white) along the white line are plotted; values below 150 correspond to wall, whereas values above 150 correspond to lumen. Whenever images did not allow a clear differentiation between lumen and wall, lumens were manually painted with white color (last five tracheids in this case). Formulas used to obtain anatomic values are presented in the upper part of the figure. B Variation in anatomical parameters' size, according to the tracheidogram method (Vaganov, 1990) to standardize earlywood to three tracheids and latewood to one. 

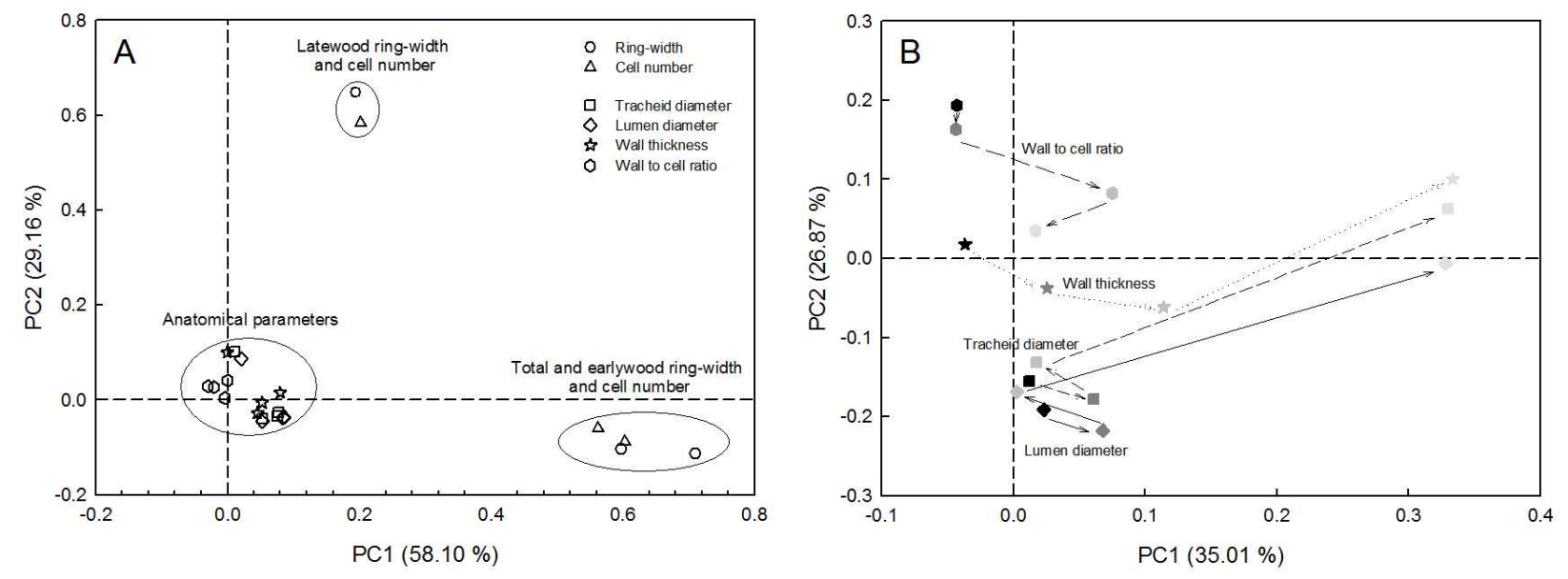

Figure 3: Biplots of the first two PC axes for A) anatomical, cell number and ring width chronologies, and B) anatomical chronologies only. Arrows and colours in figure B indicate temporal sequence from the 1st part of the earlywood (black) to the latewood (light gray). Values in brackets indicate the percentage of variance accounted for by each axis.

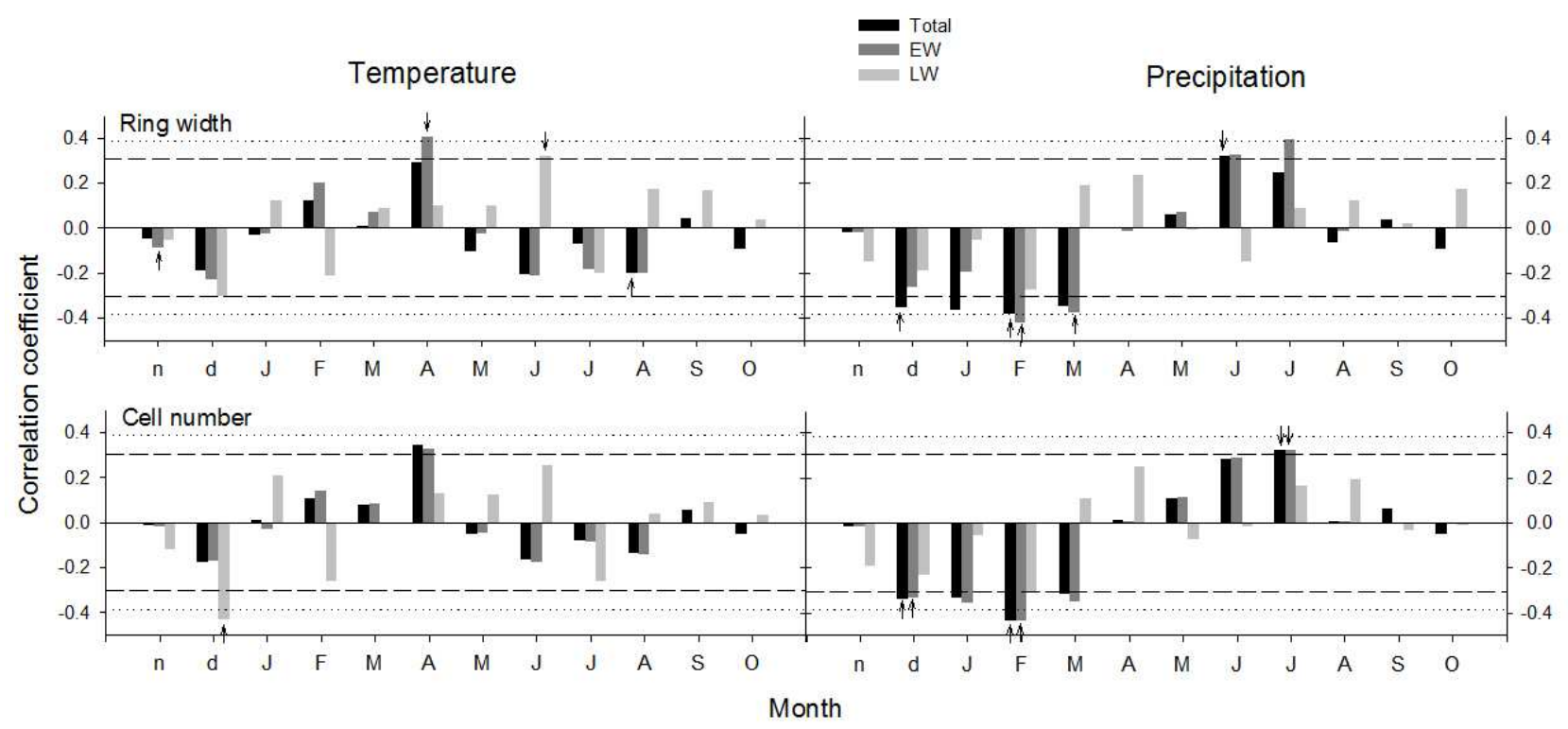

Figure 4: Correlations between ring widths, cell numbers (earlywood -EW-, latewood -LWand total ring) and monthly climatic variables (mean temperature and accumulated precipitation) for the 1965-2004 period. Dashed lines indicate the significance level $p<0.05$, and dotted ones $p<0.01$. Lowercase and uppercase letters correspond to months of the previous and current years, respectively. Arrows indicate parameters with significant values in multiple regression models. 


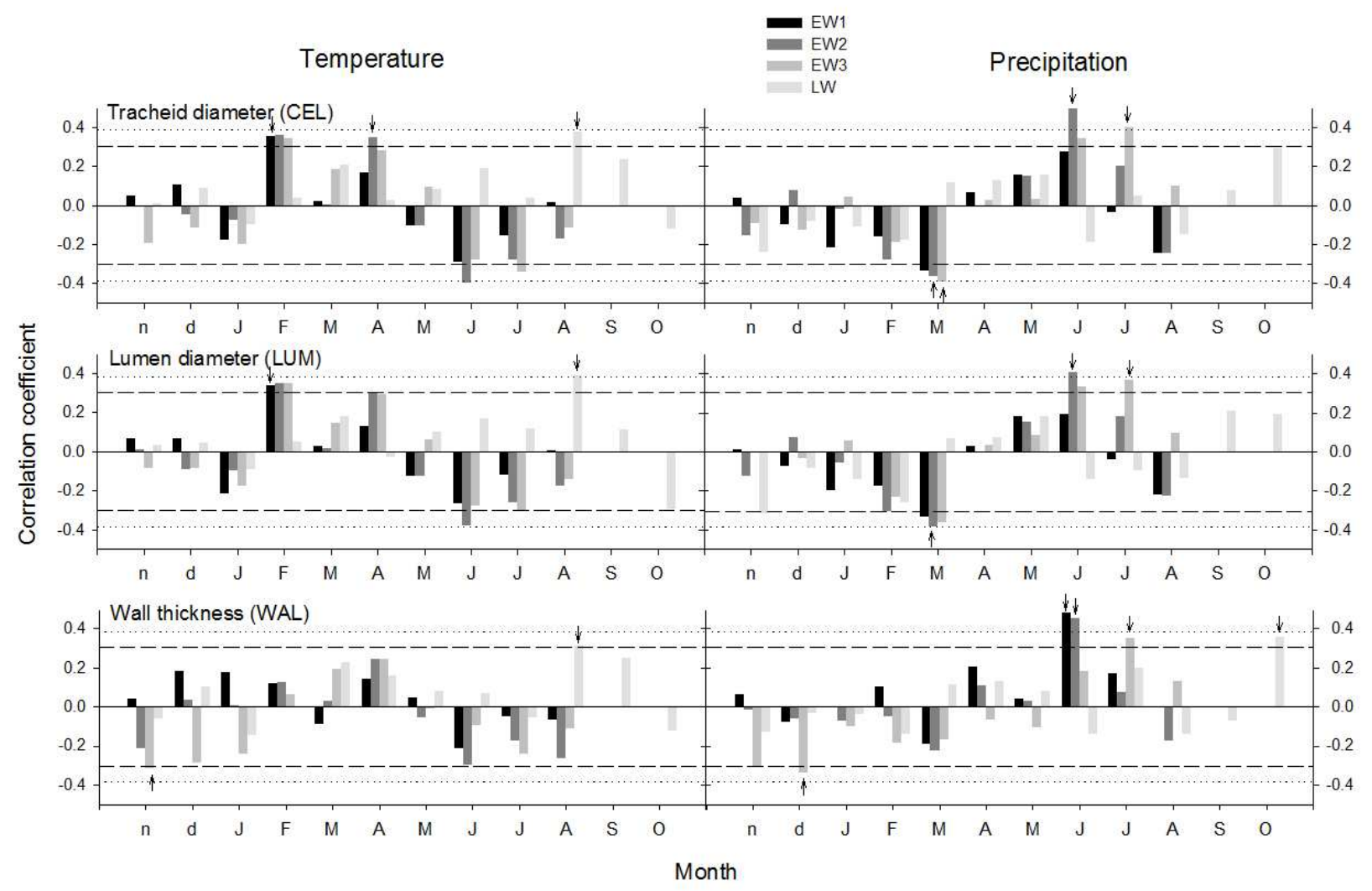

Figure 5: Correlations between anatomical variables (tracheid and lumen size and wall thickness) for different parts of the ring (earlywood 1st, 2nd and 3rd cells -EW1, EW2, EW3 respectively- and latewood-LW-) and monthly climatic variables (mean temperature and accumulated precipitation) for the 1965-2004 period. Dashed lines indicate the significance level $p<0.05$, and dotted ones $p<0.01$. Lowercase and uppercase letters correspond to months of the previous and current years, respectively. Arrows indicate parameters with significant values in multiple regression models. 

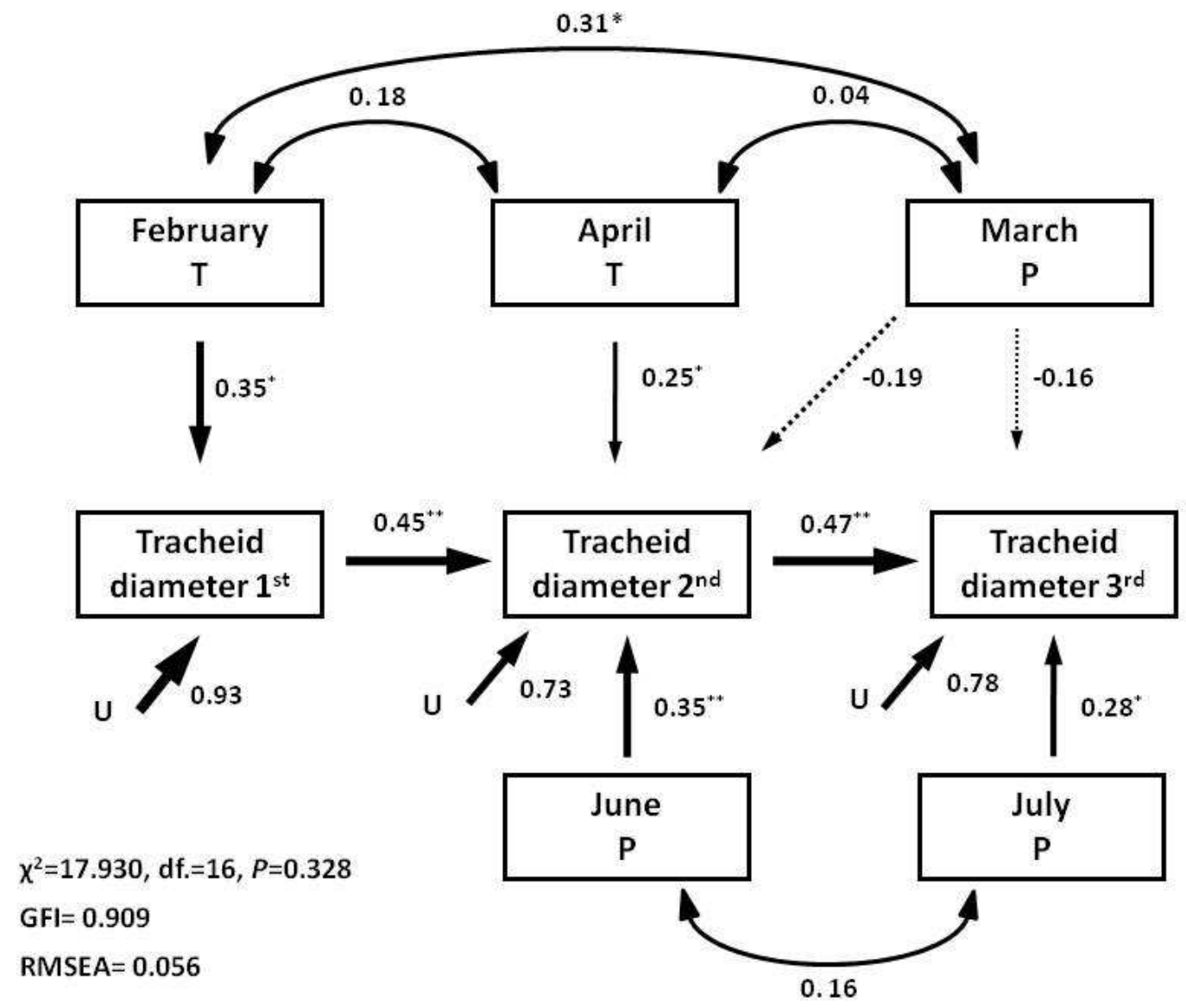

Figure 6: Structural equation model for climatic effects on earlywood tracheid diameters. Oneheaded arrows depict causal relationships whereas two-headed arrows depict correlations.

Positive effects are indicated by solid lines and negative effects by dashed lines. Arrow widths are proportional to path coefficients. Numbers in the paths indicate standardized path coefficients. Asterisks indicate significance levels: $* p<0.05 * * p<0.01$. U indicates unexplained portion of variance. 
Table 1: Summary of the statistics calculated for the ring-width, cell number and anatomical variables in the mean chronologies calculated from ten trees in the common period 1965-2004. SNR: signal-to-noise ratio; $\mathrm{ms}_{\mathrm{x}}$ : mean sensitivity: $\mathrm{r}_{\mathrm{b}}$ : mean between trees correlation; $\mathrm{R}^{2}$ climate: proportion of variance explained by climate after a multiple regression.

\begin{tabular}{|c|c|c|c|c|c|c|}
\hline Parameter & Acronym & Mean \pm SD & SNR & $\mathrm{ms}_{\mathbf{x}}$ & $\mathbf{r}_{\mathrm{bt}}$ & $\mathbf{R}^{2}$ climate \\
\hline \multicolumn{7}{|l|}{ Ring-width } \\
\hline Total & RWT & $6.52 \pm 3.46 \mathrm{~mm}$ & 2.946 & 0.187 & 0.228 & 0.424 \\
\hline Earlywood & RWEW & $\mathrm{mm}$ & 3.405 & 0.231 & 0.254 & 0.450 \\
\hline Latewood & RWLW & $2.49 \pm 1.57 \mathrm{~mm}$ & -0.103 & 0.177 & -0.017 & 0.299 \\
\hline \multicolumn{7}{|l|}{ Cell number } \\
\hline Total & CNR & cells & 3.873 & 0.174 & 0.279 & 0.377 \\
\hline Earlywood & CNEW & cells & 3.728 & 0.185 & 0.272 & 0.376 \\
\hline Latewood & CNLW & cells & 0.162 & 0.167 & 0.016 & 0.186 \\
\hline \multicolumn{7}{|l|}{ Tracheid diameter } \\
\hline Earlywood 1st part & CEL1 & $18.19 \pm 2.87 \mu \mathrm{m}$ & 1.323 & 0.037 & 0.117 & 0.124 \\
\hline Earlywood 2nd part & CEL2 & $16.93 \pm 2.69 \mu \mathrm{m}$ & 1.738 & 0.043 & 0.148 & 0.410 \\
\hline Earlywood 3rd part & CEL3 & $14.13 \pm 2.33 \mu \mathrm{m}$ & 2.167 & 0.043 & 0.178 & 0.249 \\
\hline Latewood & CELW & $6.31 \pm 1.38 \mu \mathrm{m}$ & -0.220 & 0.052 & -0.023 & 0.140 \\
\hline \multicolumn{7}{|l|}{ Lumen diameter } \\
\hline Earlywood 1st part & LUM1 & $14.82 \pm 2.74 \mu \mathrm{m}$ & 1.123 & 0.044 & 0.101 & 0.115 \\
\hline Earlywood 2nd part & LUM2 & $13.56 \pm 2.49 \mu \mathrm{m}$ & 1.393 & 0.049 & 0.122 & 0.275 \\
\hline Earlywood 3rd part & LUM3 & $11.01 \pm 2.01 \mu \mathrm{m}$ & 1.620 & 0.050 & 0.139 & 0.134 \\
\hline Latewood & LULW & $3.49 \pm 0.92 \mu \mathrm{m}$ & -0.396 & 0.058 & -0.041 & 0.266 \\
\hline \multicolumn{7}{|l|}{ Wall thickness } \\
\hline Earlywood 1st part & WAL1 & $3.38 \pm 0.66 \mu \mathrm{m}$ & 0.001 & 0.043 & 0.000 & 0.230 \\
\hline Earlywood 2nd part & WAL2 & $3.37 \pm 0.66 \mu \mathrm{m}$ & -0.447 & 0.028 & -0.047 & 0.204 \\
\hline Earlywood 3rd part & WAL3 & $3.12 \pm 0.59 \mu \mathrm{m}$ & 0.547 & 0.046 & 0.052 & 0.383 \\
\hline Latewood & LWW & $2.82 \pm 0.63 \mu \mathrm{m}$ & 0.376 & 0.052 & 0.036 & 0.219 \\
\hline \multicolumn{7}{|l|}{ Wall to cell ratio } \\
\hline Earlywood 1st part & WC1 & $0.24 \pm 0.06$ & 0.302 & 0.051 & 0.029 & 0.000 \\
\hline Earlywood 2nd part & WC2 & $0.25 \pm 0.06$ & -0.248 & 0.040 & -0.025 & 0.126 \\
\hline Earlywood 3rd part & WC3 & $0.29 \pm 0.05$ & -0.036 & 0.034 & -0.004 & 0.103 \\
\hline Latewood & LWWC & $0.45 \pm 0.05$ & -0.198 & 0.028 & -0.020 & 0.276 \\
\hline
\end{tabular}

